\title{
Fixed Bed Adsorption of Natural Organic Matter Using Ozonated Carbon Active
}

\author{
Adi Kurniawan ${ }^{1}$, Dian Listiyani ${ }^{1}$, Jono Suhartono ${ }^{1 *}$, and Suparman Juhanda ${ }^{1}$ \\ ${ }^{1}$ Chemical Engineering Department, Institut Teknologi Nasional \\ J1 PHH. Mustofa no 23 Bandung 40124, Indonesia
}

\begin{abstract}
Nowadays water, one the most important substance in human life, are being much polluted by not only industrial activities but also caused by human activities and natural polluted material. One of the natural impurities that commonly occur in water is Natural Organic Matter (NOM). NOM are extracted organic compounds from soils, plants, or decomposed animals that infiltrate into the water body when the water contacts with those materials. Thus, the presence of NOM in water body is inevitable. Many techniques have been applied to remove this impurity such as coagulation, flocculation, and filtration. In this research, NOM were controlled using ozonated activated carbon in a fixed bed adsorption system. There were two parameters studied that are activated carbon ozonation time that ranging from $5-25$ minutes and the fixed bed height of $1-7.5 \mathrm{~cm}$. Interestingly, the investigation showed that the optimum condition for the bed height was obtained at $6 \mathrm{~cm}$ whilst the optimum carbon active ozonation time was at 5 minute. The experiment was concordant with the conducted BET analysis that showed the highest activated carbon surface area at 5 minute compared to other ozonation time. The ozonated activated carbon was also found to be have slightly better adsorption performance compared to unozonated activated carbon bought from the market with capacity of ozonated activated carbon adsorption was found to be $6.12 \times 10^{-9} \mathrm{mg} / \mathrm{g}$.
\end{abstract}

\section{Introduction}

Clean water has an important role in daily life. However, clean water becomes difficult to find due to varied impurities contained in water. One of the impurities is Natural Organic Matter (NOM), an organic compound that came from decomposition and metabolic reaction of plants and animals. NOM compounds usually consisted of protein, polysaccharide, and aromatic compounds.

NOM is not a single substance but composed of many components. Those components are humin, humic acids, and fulvic acids (Frimmel and Abbt-Braun, 1999; Peuravuori et al, 2002). The difference between those three major NOM compounds may indicate from their solubility through $\mathrm{H}$ condition. Humin are insoluble in any $\mathrm{pH}$, fulvic acid are soluble in any $\mathrm{pH}$ whilst humic acid are only soluble at $\mathrm{pH}$ above 3 (Fulcrum Health Limited, 2004). Humic acid is the largest compound in the NOM constituents, thus humic acid may serve as a parameter content of NOM in the water.

NOM concentration in water must be reduced because it can react with chlorine and chloramines to produce disinfection by-product such as trihalomethanes and haloacetic acid which considered to be carcinogenic and genotoxic (Gora S, 2011).

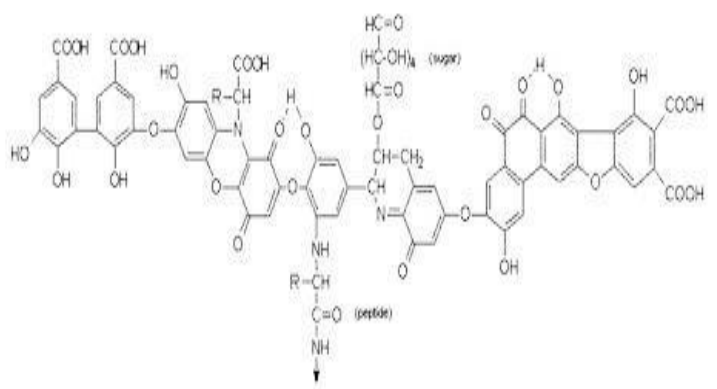

Fig. 1. Structure humic acid (Stevenson,1982)

In order to minimise the production of disinfection by-products in water, it must be controlled by removing or reducing the NOM concentration in feed water before disinfection process, thus production of trihalomethanes and haloacetic acids can be reduce. There are many method to control NOM concentration in water such as coagulation - floculation, membrane, adsorption, and ozonation.

Adsorption is a phenomenon when substance adheres to a surface of another substance caused by the attraction of force from each substance. Adsorption process can be conducted either in batch or continuous system. Activated carbon is the most applicable adsorbent uses 
as adsorbent media in the adsorption process because it has a large surface area, easy to produce, cheap, nontoxic, easy and economical to be regenerated.

Activated carbon can be modified by using ozone either to expand their surface area or to modify their surface functionalization. The ozonation of activated carbon may form oxidation bond to the carbon surface such as carboxylic (C-OO), carbonyl $(\mathrm{C}=\mathrm{O})$, and hidroxyl $(\mathrm{C}-\mathrm{OH})$ through Griegge's mechanism (Ke peng et al, 2011). In this research, NOM were controlled using ozonated activated carbon in a fixed bed adsorption system. To know the efficiency of activated carbon to adsorb the NOM content in water. There were two parameters studied that are activated carbon ozonation time that ranging from 5 - 25 minutes and the fixed bed height of $1-7.5 \mathrm{~cm}$. Continuous adsorption process which processed can be observed using breakthrough curves. The output yields can be described by using breakthrough curve between output concentration versus output volume.

\section{Material \& methods}

The materials used in this research were humic acid (Sigma Aldrich, Singapore), $\mathrm{NaOH}$, activated carbon, and $\mathrm{HNO}_{3}$ were bought from Brataco, Indonesia, Deionisation water. The research stages was conducted was started from preparation of activated carbon, ozonation of activated carbon, preparation of humic acid solution for calibration and feed, adsorption process, and finally the humic acid concentration analysis.

\subsection{Preparation of Activated Carbon and Ozonated Activated Carbon}

This process is carried out for the preparation of activated carbon before activated carbon used as absorbent bed on adsorption process. Firstly, activated carbon was crushed into a smalled size using a mortar. Then the smaller activated carbon is filtered using a mesh filter to obtained $20 / 35$ mesh particle size. Furthermore, the 20/35 mesh size activated carbon washes using deionisation water to eliminate dust from crushing process. Finally, the activated carbon was modified using ozone for 5, 10, 15, 20, and 25 minutes.

\subsection{Preparation of Humic Acid Stock Solution}

0.1 grams of $\mathrm{NaOH}$ was poured into a $500 \mathrm{~mL}$ volumetric flask and dissolved it by $250 \mathrm{~mL}$ deionisation water, 0.5122 grams humic acid then was added into the $\mathrm{NaOH}$ solution. Stir the humic acid solution for 15 minutes, and add another deionisation water until the marked line. The agitation was extended for 3 hours until homogeneous solution obtained. The next step was filtering the solution using vacuum filter through 0,45 $\mu \mathrm{m}$ membrane filter. This stock solution was stored in a cool and dark place to preserve them for long term utilization.

In order to prepare a $10 \mathrm{mg} / \mathrm{L}$ humic acid solution feed, a $20 \mathrm{~mL}$ humic acid stock solution was pipetted and diluted using deionisation water to obtain $2 \mathrm{~L}$ humic acid solution. The solution was then stirred for about 30 minutes to obtain homogeneous solution.

\subsection{Adsorption Process}

The adsorption process was conducted in a continuous fixed bed adsorption column. The bed column dimension was $2.5 \mathrm{~cm}$ diameter to $30 \mathrm{~cm}$ height. The solution feed was poured into a feed tank and pumped to a constant head tank. The feed flowrate went into the bed column was controlled using a valve and maintained at $0.5 \mathrm{~cm}^{3} / \mathrm{s}$. Meanwhile, the overflow of constant head tank was returned into the feed tank.

The output of adsorption column was analysed every $2,5,10,20,35$ and 65 minutes to accommodate the breakthrough condition has been yielded. The adsorption process was conducted in a varied height of absorption beds which are $1.5 ; 3 ; 4.5 ; 6$; and $7.5 \mathrm{~cm}$. The step was repeated for varied ozonated activated carbon time which ozonated for $5,10,15,20$, and 25 minutes.

\subsection{Analysis of Humic Acid Concentration and Activated Carbon Pore Size}

The humic acid concentration was analyzed using UVVIS Spectrophotometer (Genesis Thermo Scientific, USA) at $254 \mathrm{~nm}$ wavelength (Standard Method). The spectrophotometer was heated for 15 minutes. Then put a blank solution into the spectrophotometer to set up its absorbance value exact to zero before it uses for sample analysis.

The mean pore size of activated carbon was analysed using BET (Brunauer-Emmett-Teller) (Nova 3200e, Quantachrome,UK). Determination of the surface area of the substrate is to be done by physical adsorption of the gas (usually nitrogen). Gas molecules that stick to the surface of the substrate solid (adsorbent) are said to be adsorbed and tend to form a thin layer that covers the entire adsorbent surface.

\section{Result}

\subsection{Standardization Curve}

Standardization curve was obtained from measurement of humic acid standard solution which is measured at determined wavelength, i.e $254 \mathrm{~nm}$ using variation concentration $2,5,10,15$, and $20 \mathrm{mg} / \mathrm{L}$. 


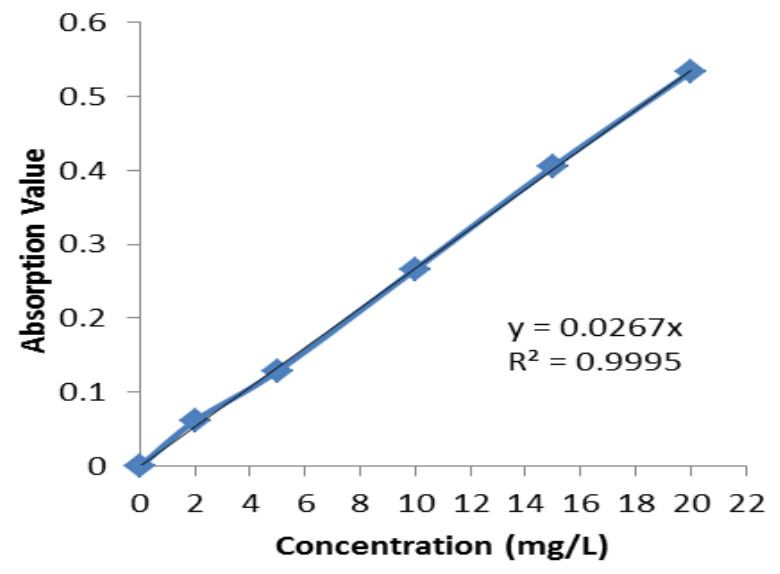

Fig. 2. Standardization curve of humic acid

Figure 2 shows the standardization curve with obtained trend line equation of $\mathrm{y}=0.0267 \mathrm{x}$ and confidence level of determination, $\mathrm{R}^{2}$, is 0.9995 . This humic acid standardization curve was made to calculate the concentration of humic acid solution used in the feed and the output concentration of humic acid.

\subsection{Influence of Ozonated Time}

The adsorption process was done using activated carbon which has been modified with different ozonisation time, i.e. $5,10,15,20$, and 25 minutes. The activated carbon bed height and NOM concentration feed was set up at $4.5 \mathrm{~cm}$ and $10.3 \mathrm{mg} / \mathrm{L}$. The aim was to study the optimum process of modified activated carbon by different ozonisation time, to minimize NOM concentration.

It is shown in fig 3, the influence of ozonisation time against output concentration obtained from $10.3 \mathrm{mg} / \mathrm{L}$ of NOM concentration that the optimum modified activated carbon absorption was found at 5 minute of ozonisation time. Figure 3 also shows that longer ozonisation time will decrease activated carbon ability to adsorb NOM. It is indicated by the first 2 minute of adsorption process, NOM removal were $2.63,1.92,0.76,1.61$, and 0.60 $\mathrm{mg} / \mathrm{L}$ for ozonated activated carbon at 5, 10, 15, 20, and 25 minutes, respectively. The concentration getting from plotted absorbance spectro analysis to standarization curve, for each ozonised carbon time of 5, 10, 15, 20, and 25 minutes, respectively.

Figure 3 shows that the longest saturation of carbon bed was obtained by carbon with ozonation time of 5 minutes. However, the saturation time among the varied ozonation time was insignificant and most of the breakthrough point was obtained around 10 minutes. The longest saturation obtained by 5 minutes ozonation time was caused by larger specific surface area of carbon at 5 minutes ozonation time compared to further ozonation time. The specific surface area of 5 minutes ozonation time was $154.71 \mathrm{~m}^{2} / \mathrm{g}$ whilst further ozonation decrease the carbon surface area to 1.75 after 25 minutes ozonation time. Table 1 shows the specific surface area of ozonated and un-ozonated carbon.

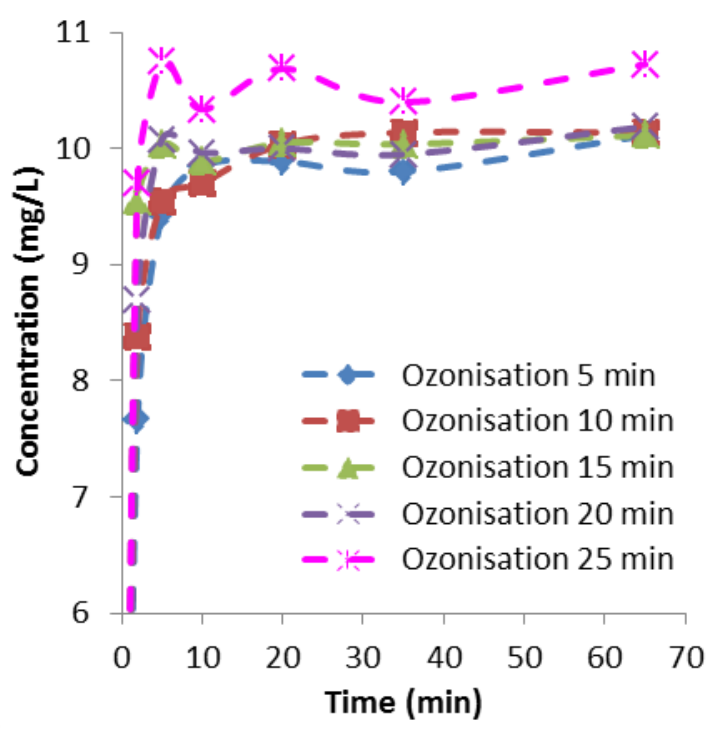

Fig. 3. Continuous adsorption of NOM on humic acid at bed height of $4.5 \mathrm{~cm}$

The surface area at 5 minutes ozonation is larger than 15 and 25 minutes ozonation. This might be caused by the longer ozonisation time apply, the reaction of ozone and the impurity in the carbon pores becomes more intensive. Moreover, oxidation product of carbon impurity pores may cover and reduce activated-carbon surface area.

Table 1. Surface Area of Ozonated and Un-ozonated Carbon

\begin{tabular}{|c|c|}
\hline Activated Carbon & $\begin{array}{c}\text { Surface Area } \\
\left(\mathrm{m}^{2} / \mathrm{g}\right)\end{array}$ \\
\hline Without Ozonisation & 41.723 \\
\hline 5 minute & 154.713 \\
\hline 15 minute & 71.079 \\
\hline 25 minute & 1.746 \\
\hline
\end{tabular}

The reduction of carbon surface area resulted in less ability of activated carbon to accommodate the high NOM solute concentration thus shorter saturation time of the bed as shown in figure 3 . The output concentration of 25 minutes ozonation time shows higher value than the initial concentration used. This might be caused by the high amount of exuviating activated-carbon intruding into the output through the adsorption process.

\subsection{Bed Height Variation}

The adsorption process in this step was using 15 minutes ozonated activated carbon and different height of carbon bed that are $1.5,3,4.5,6$, and $7.5 \mathrm{~cm}$. 


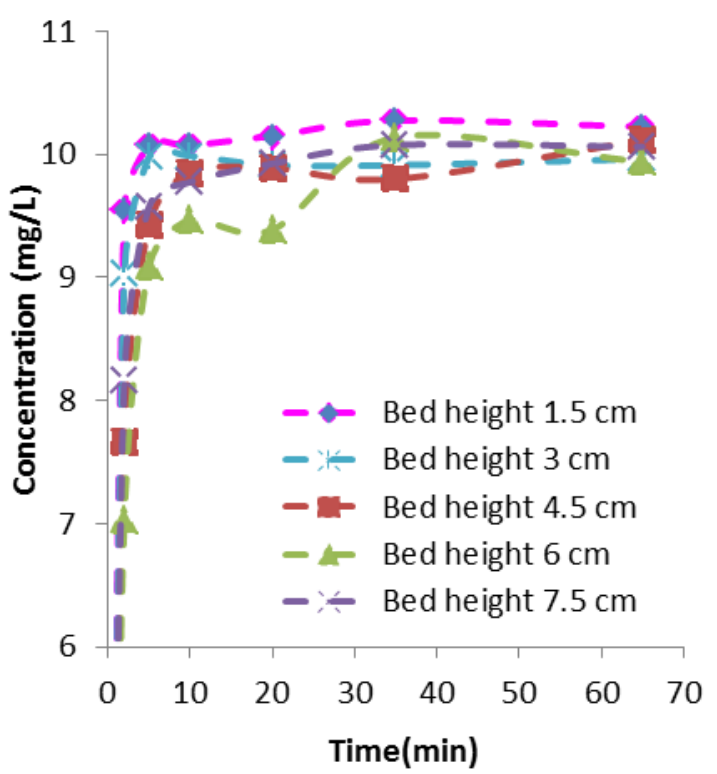

Fig. 4. Continuous adsorption of NOM on humic acid at ozonated time $5 \mathrm{~min}$

The lowest concentration of NOM absorption in the first 2 minutes was obtained at $7.5 \mathrm{~cm}$ bed height while the highest concentration was obtained at $1.5 \mathrm{~cm}$ bed height as shown in fig 4. The utilization of higher of carbon bed height resulted in higher absorption capability of the carbon to adsorb NOM. However, carbon bed ability to adsorb NOM was declined as process time conducted. This was caused by the increasing of solutes adsorbed in the carbon surface, as shown by the output concentrations which is obtained from the sample at specific intervals on fig 4.

Although the capability of carbon to adsorb NOM increasing as the addition of bed height, the highest absorption was obtained from $6 \mathrm{~cm}$ bed height as shown in fig 4. The saturation time of $6 \mathrm{~cm}$ bed height was delayed compared to $7.5 \mathrm{~cm}$ bed height. This phenomenon might occur due to the influent feed was difficult to pass $7.5 \mathrm{~cm}$ bed height of activated-carbon since increasing bed height will also increase the bed retention which generated by higher pressure drop in the bed. Thus, high pressure drop occurs in the bed will result in smaller output rate obtained from the adsorption bed that made NOM retained, adsorbed and accumulated in the activated-carbon longer than shorter activated carbon bed. On contrary, the output concentration of 7,5 $\mathrm{cm}$ height is higher than $6 \mathrm{~cm}$ bed height since the bed was quickly saturated by the retained NOM.

\subsection{Comparison of Activated Carbon from Market and Ozonated Activated Carbon}

The performance of optimised ozonated activated carbon process was compared to pristine activated carbon bought from market. The result is presented on the figure 5 .

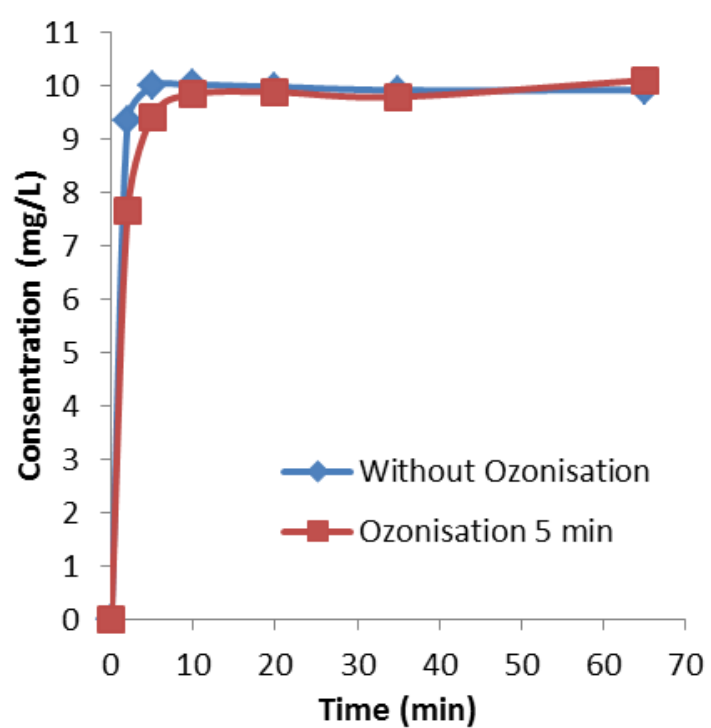

Fig. 5. Breakthrough curve comparison between with and without ozonisation

The data shows that the result obtained from the absorption capability of activated carbon modified by ozone was able to perform higher absorption capability compared to pristine activated carbon bought from market. It can be seen from figure 5 where activated carbon modification and activated carbon from market at the first 2 minute adsorption process. The NOM concentration obtained from output of fixed bed adsorption was $2.559 \mathrm{mg} / \mathrm{L}$ for ozone modified activated carbon and $0.861 \mathrm{mg} / \mathrm{L}$ for pristine activated carbon where the feed concentration used was $10.3 \mathrm{mg} / \mathrm{L}$. This is caused by the surface area of modified activated carbon were much larger than the pristine activated carbon. Moreover, the introduction of ozone may generate oxidized compounds in the activated carbon surface which makes activated carbon more reactive to adsorb the natural organic matter. According to (Naeimi, 2009) ozonation of carbon will produce oxidation bond in carbon surface area such as carboxylic (C-OO), carbonyl $(\mathrm{C}=\mathrm{O})$, and hydroxyl $(\mathrm{C}-\mathrm{OH})$. Therefore, the activated carbon which has been modified by the ozone may able to accommodate higher solute absorbed than pristine activated carbon bought from market which was not ozonised.

Figure 5 also shows the comparison of these two activated carbon types used based on saturation time. The breakthrough curve shows that pristine activated carbon had faster saturation time comparing to ozonated activated carbon. The pristine activated carbon was saturated at the first 5 minutes operation whilst ozonated activated has double length of saturation time compare to pristine activated carbon. This may be caused by the activated carbon bought from market has lesser capability to adsorb the solute since their surface area were smaller compared to ozonated activated carbon as shown in table 1 . The concentration of NOM in the output of fixed bed adsorption that almost reached to its initial feed value indicates the saturation of activated carbon bed itself. 


\subsection{Thomas Equations}

Thomas equation is the equation that commonly used for approaching a continuous adsorption process in order to find out the mass transfer constant rate $(\mathrm{k})$, and mass transfer capacity of adsorption (qo). A linearization of equation into logarithmic approach

$$
\ln \left(\left(\frac{C_{g}}{c_{\mathrm{t}}}\right)-1\right)
$$

to volume of fixed bed adsorption output obtained from the experiment breakthrough curve is demanded to solve this Thomas equation. The linearization is shown in the figure 6.

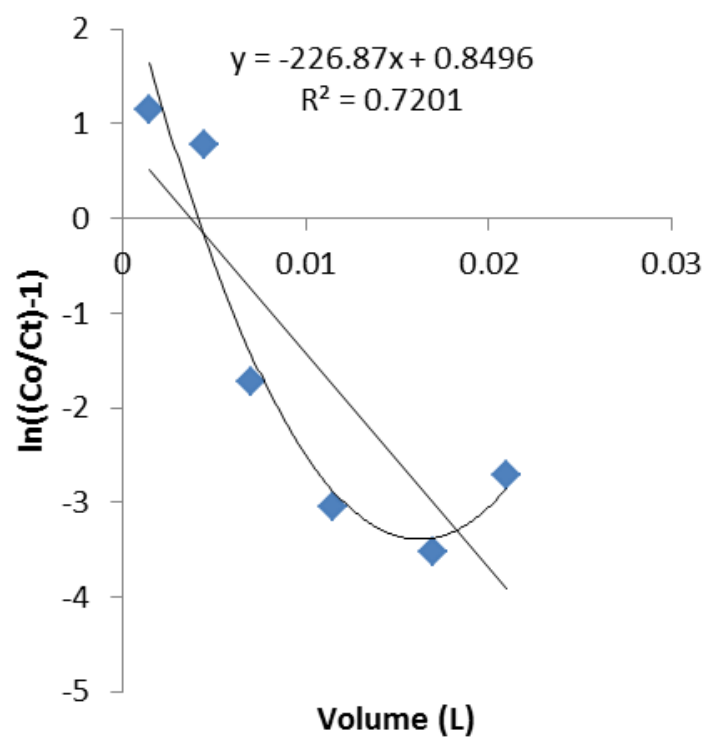

Fig. 6. Linearization curve of Thomas equation at bed height $4.5 \mathrm{~cm}$ and ozonated time $5 \mathrm{~min}$

Figure 6 shows the slope and intercept value of the linearization of the breakthrough curve. It is obtained that mass transfer rate $(\mathrm{k})$ value is $1,07 \times 10^{-2} \mathrm{~L} / \mathrm{g}$.s and the adsorption capacity (qo) is $6,12 \times 10^{-3} \mathrm{mg} / \mathrm{g}$. These values indicate that absorbance from activated carbon used in the conducted experiments was small. Absorption capability and small constant rate indicates that mass of adsorbent used were too small compared to the applied NOM feed concentration. The consequence of these, the activated carbon used performed less capability to adsorb the mass of NOM solution. Furthermore, the activated carbon was easily saturated by high concentration of NOM used. In order to obtained better absorption ability of activated carbon, it is required to have a proportional mass of activated carbon used to mass of feed NOM since the concentration of adsorbed NOM is directly proportional to the amount of activated carbon used as the adsorbent.

\section{Conclusion}

The ozonation process of activated carbon was conducted at $5,10,15,20$, and 25 minutes whilst the activated carbon particle size was $20 / 35$ mesh. The optimum condition obtained for this ozonation time is 5 minutes, since longer ozonation time will result in destruction of activated carbon pores and causing exuviating and decreasing of activated carbon pores. Therefore, ozonation after 5 minutes will reduce activated carbon surface area.

The activated carbon fixed bed height was set up at $1.5 ; 3 ; 4,5 ; 6$; and $7.5 \mathrm{~cm}$. It is obtained the optimum condition of fixed bed height was at $6 \mathrm{~cm}$. Higher activated carbon bed applied increases activated carbon absorption capacity. Thus, more NOM can be absorbed in the adsorbent. However, whenever bed height was too high, it will cause increasing of retention due to the increasing of pressure drop that may disturb the influent rate and causing activated-carbon becomes quickly saturated.

Natural Organic Matter (NOM) might be processed using adsorption method by activated carbon as the adsorbent materials. However, ozonized activated carbon will perform higher absorption capability than pristine activated carbon. The process of ozonisation affects the surface area of the carbon. On the other hand, if the ozonisation time is taking more than 5 minutes, ozone will damage and decrease the carbon surface area.

Adi and Dian would like to appreciate to Mr Teddy Irnata who has helped the writer to design an instrument that is used in the research, and to Mr Nurcaya who has helped to fund the research.

\section{References}

1. Frimmel, F.H. and Abbt-Braun, G. Enviromental International, 25 (2/3), 191-207 (1999)

2. Fulcrum Health Limited. Humifulvate-a natural active ingredients. p. 1-43. Budapest: Humifulvate science, (2004)

3. Gora, S. Study on Characteristics and Removal of Natural Organic Matter in Drinking Water System in Newfoundland and Labor, (2011)

4. Ke peng, et al., Karbon. 49, 70-76 (2011)

5. Naeimi, H., et al., Applied Surface Science, 256, 631-635 (2009)

6. Peuravuori, J., et al., Water Research, 36, 45524562 (2002)

7. Stevenson, F.J., Humus Chemistry. Genesis, Composition, Reactions (John Wiley and Sons Ltd : $\mathrm{N}, 1982$ ) 